\title{
PRODUÇÃO DE BIOMASSA PARA GERAÇÃO DE ENERGIA EM POVOAMENTOS DE Pinus taeda L. COM DIFERENTES IDADES ${ }^{1}$
}

Martha Andreia Brand², Thielly Schmidt Furtado Stähelin ${ }^{3}$, Juliana Ceccato Ferreira ${ }^{4}$ e Márcio Daian Neves ${ }^{5}$

RESUMO - Os objetivos deste trabalho foram quantificar e qualificar a biomassa residual produzida em plantios comerciais de Pinus taeda L., em diferentes idades e sistemas de manejo, visando à geração de energia em sistemas de cogeração. As idades dos povoamentos foram: três anos (primeira poda), seis anos (terceira poda), 10 anos (terceira poda), 12 anos (primeiro desbaste), 14 anos (primeiro desbaste), 16 anos (segundo desbaste) e 24 anos (corte raso). Cinco árvores foram colhidas em cada idade, e seus componentes separados, pesados e analisados quanto ao teor de umidade e ao poder calorífico. Os dados quantitativos e qualitativos foram correlacionados para determinar o potencial de geração de energia elétrica a partir da biomassa florestal. Os plantios de Pinus taeda L. produziram de 30 a 95 t de biomassa florestal/ha, respectivamente, aos 3 e 24 anos de idade. O maior potencial produtivo de biomassa para a geração de energia são o corte raso (24 anos), o primeiro desbaste (14 anos) e a terceira poda (10 anos), respectivamente. O material com melhor qualidade para geração de energia foi o galho, com o menor teor de umidade (54\%) e o maior poder calorífico líquido $(1.784 \mathrm{kcal} / \mathrm{kg})$, sendo 24, 14 e 10 anos as melhores idades. O sistema de manejo e as práticas silviculturais têm influência, juntamente com a idade, na produção de biomassa por unidade de área. O rendimento energético da biomassa recém-colhida é baixo, necessitando de tratamento prévio para redução do teor de umidade e aumento do poder calorífico líquido.

Palavras-chave: Resíduos; Eficiência energética; Cogeração.

\section{PRODUCTION OF BIOMASS FOR ENERGY GENERATION IN PLANTATIONS OF Pinus taeda L. WITH DIFFERENT AGES}

\begin{abstract}
The objectives of this study were to quantify and qualify the residual biomass produced in commercial plantations of Pinus taeda $L$. in different ages and management systems, aiming at generating energy in co-generation systems. The ages of the forests were: 3 years (first pruning), 6 years (third pruning), 10 years (third pruning), 12 years (first thinning), 14 years (first thinning), 16 (second thinning) and 24 years (harvesting). Five trees were harvested at each age and their separate components were weighed and analyzed for moisture content and calorific value. Quantitative and qualitative data were correlated to determine the potential for generating electricity from forest biomass. The plantations of Pinus taeda L. produced 30-95 tonnes of forestry biomass/ha, respectively, at 3 and 24 years of age. The highest yield potential of biomass for energy generation are harvesting (24 years), first thinning (14 years) and third pruning (10 years), respectively. The best quality material for power generation was the branch with the lowest moisture content (54\%) and higher net calorific value $(1784 \mathrm{kcal} / \mathrm{kg})$, and the best ages were 24, 14 and 10 years. The management system and forestry practices have an influence, together with age on biomass production per unit area. The energy performance of newly harvested biomass is low, requiring treatment to reduce the moisture content and increase in net calorific value.
\end{abstract}

Keywords: Residues; Energetic efficiency; Cogeneration.

\footnotetext{
${ }^{1}$ Recebido em 20.05.2010 aceito para publicação em 27.02.2014.

${ }^{2}$ Departamento de Engenharia Florestal, Universidade do Estado de Santa Catarina, UDESC, Brasil. E-mail: <a2mab@cav.udesc.br>.

${ }^{3}$ Departamento Nacional de Infraestrutura de transportes, DNIT. E-mail: <thiellysf@hotmail.com>.

${ }^{4}$ Mestrado em Bioenergia, Universidade Federal do Paraná, UFPR, Brasil. E-mail: <cf.juliana@yahoo.com.br>.

${ }^{5}$ Tractebel Energia S.A.. E-mail: <mneves@tractebelenergia.com.br>.
} 


\section{INTRODUÇÃO}

Segundo o Ministério de Minas e Energia (BRASIL, 2011), a oferta interna de energia no Brasil teve como principais representantes o petróleo e derivados, com $47,9 \%$, a biomassa com $27,1 \%$ e a energia hidráulica e elétrica com 14\%, em 2010. O que se observou ainda é que esses dados não se alteraram significativamente ao longo dos últimos anos, apresentando, inclusive, tendência de aumento do uso da biomassa no futuro.

Em comparação com o mundo, a matriz energética brasileira é considerada limpa pelo uso intensivo das fontes de energia renováveis. Nesse aspecto, a biomassa tem grande representatividade, no entanto ainda não recebe o destaque merecido no balanço energético nacional.

Mesmo com a importância atual da biomassa, esta fonte de energia pode se tornar ainda mais promissora se for incluído o uso dos resíduos e matérias-primas oriundas das atividades de base florestal, tanto da floresta quanto da indústria, para a geração de energia, principalmente elétrica.

Para promover o desenvolvimento mais intenso dessa fonte energética, são necessárias informações da capacidade produtiva da biomassa para o uso energético e dos riscos potenciais do seu uso para o ambiente, em comparação com as outras fontes energéticas. Deve-se ainda verificar se haverá ganhos sociais e econômicos em função da geração de emprego e renda a partir da criação e desenvolvimento do mercado de resíduos.

Estudos de quantificação e qualificação da biomassa da indústria madeireira realizados a partir de 2001 e experiências industriais do uso da biomassa para geração de energia elétrica, oriunda de indústrias de base florestal, a partir de 2005, na região Serrana Sul de Santa Catarina, vêm demonstrando o grande potencial econômico, social e ambiental do uso dessa fonte para a geração de energia (BRAND et al., 2001; BRAND; NEVES, 2005; BRAND et al., 2009).

Em termos econômicos, os ganhos observados foram através do aumento da renda das indústrias com a venda dos resíduos, surgindo um novo mercado na região (HOFF et al., 2008). Os ganhos sociais envolvem postos de trabalho e inclusão de novas empresas na cadeira produtiva da energia; em termos ambientais, pela redução de passivos ambientais, quando eram gerados pelo acúmulo dos resíduos industriais nos pátios da indústria e de aterros e comercialização dos créditos de carbono pela planta de geração de energia elétrica a partir da biomassa.

Em 2012, a quantidade de biomassa mais utilizada é a originária das indústrias de transformações primária e secundária da madeira, em razão da extensa área de plantios florestais em Santa Catarina, com 538.254 ha, concentrados nas regiões do Planalto Sul e Norte do Estado e pertencentes a grandes empresas com plantios com mais de 100.000 ha (ABRAF, 2012). Além das indústrias de transformação, o processo de produção florestal é responsável pela geração de resíduos como galhos finos, acículas e casca, além das operações silviculturais de poda, desbaste até o corte raso.

A elevação dos preços dos resíduos oriundos da indústria e o surgimento de novas alternativas de uso desses resíduos no mercado geraram a necessidade de estudos para a quantificação e qualificação da biomassa gerada nas florestas.

A geração de resíduos ao longo do processo de produção florestal do Pinus spp. é uma realidade na região do Planalto Sul catarinense (Lages), desde as atividades silviculturais de poda e desbaste até o corte raso, em que são gerados materiais não comercializáveis, como galhos finos, acículas e casca.

Segundo Soares et al. (2003), os valores obtidos indicaram que a colheita florestal, visando ao sistema de uso múltiplo, apresenta mais lucro que o uso único. Assim, os multiprodutos demonstraram ser a melhor alternativa de remuneração do produto advindo de povoamentos florestais. Além disso, as condições climáticas e de solo, bem como a idade, contribui para a variação da quantidade de biomassa produzida em um povoamento, como observou Santana (2008), quando avaliou plantios de Eucalyptus em diferentes idades e regiões de plantios.

Nesse contexto, o objetivo deste trabalho foi quantificar e qualificar a biomassa residual produzida em plantios comerciais de Pinus taeda, em diferentes idades e sistemas de manejo, visando à geração de energia em sistemas de cogeração. 


\section{MATERIAL E MÉTODOS}

A biomassa florestal foi coletada em povoamentos de Pinus taeda L., localizados nos Municípios de Correia Pinto e Bocaina do Sul, no Estado de Santa Catarina, em sete idades. Além das idades, foram selecionadas diferentes etapas de manejo da floresta (Tabela 1).

Aos 3 e 6 anos de idade, foi retirado em torno de 50 a 70\% da copa de todas as árvores do povoamento, sendo o procedimento de poda realizado por funcionário da empresa, em que se determinou a massa do material obtido na poda. Aos 10 anos de idade, as árvores foram podadas com supressão de 50\% da copa das árvores.

Ocorreram dois desbastes, sendo o primeiro feito aos 12 e 14 anos e, o segundo, aos 16 anos. Em cada um dos desbastes, a supressão foi de $50 \%$ das árvores. O corte final foi feito aos 24 anos. O cálculo da biomassa por unidade de área para geração de energia foi feito a partir das árvores retiradas.

A avaliação das árvores consistiu na medição do DAP, altura total e comercial (diâmetro mínimo de 8 cm de ponta fina) em cinco árvores em cada povoamento dentro de uma parcela de 10 x10 m. De cada uma das árvores foram coletados, separadamente, galhos livres de folhas, acículas, copa (parte do tronco com diâmetro inferior a $8 \mathrm{~cm}$, livre de galhos e folhas) e discos na base, DAP e aos 25, 50, 75 e 100\% da altura comercial (até o diâmetro mínimo de $8 \mathrm{~cm}$ ), para a determinação das propriedades energéticas da biomassa.
Neste estudo foi coletado em campo cada componente separadamente, sendo todas as folhas (acículas) retiradas dos galhos, e a copa consistiu na parte do tronco com diâmetro inferior a $8 \mathrm{~cm}$, livre de galhos e folhas. Assim, cada árvore foi separada em quatro componentes: fuste comercial com diâmetro superior a $8 \mathrm{~cm}$ de ponta fina (que não foi medido no estudo); folhas (acículas); galhos livres de folhas e copa, livre de galhos e folhas. As acículas, copa e galhos de cada árvore foram pesados separadamente para determinar a produção individual das árvores. Posteriormente, foram calculados os valores médios de cada componente, sendo estes extrapolados para a unidade de área.

No laboratório, o material foi preparado para as análises, seguindo as normas: NBR 14929 para teor de umidade e DIN 51900 para poder calorífico superior e líquido 6 .

O potencial de geração de energia elétrica a partir da biomassa florestal residual foi calculado a partir de dados previamente conhecidos, oriundos da experiência do uso da biomassa florestal entre 2005 e 2012, no sistema de cogeração instalado na cidade de Lages, no Estado de Santa Catarina, da planta de cogeração Lages da empresa Tractebel Energia S.A.

Poder calorífico líquido médio da biomassa de 1.550 $\mathrm{kcal} / \mathrm{kg}$ (valor da biomassa florestal utilizada na cogeradora), determinado em bomba calorimétrica no

Tabela 1 - Condições dos povoamentos de Pinus taeda utilizados para a quantificação e qualificação da biomassa florestal na região de Lages, SC.

Table 1 - Management of Pinus taeda plantations used for the quantification and qualification of forest biomass, Lages, SC, Brazil.

\begin{tabular}{cccccc}
\hline Idade & $\begin{array}{c}\text { Número } \\
\text { árvores (ha) }\end{array}$ & $\begin{array}{c}\text { Árvores } \\
\text { retiradas }\end{array}$ & $\begin{array}{c}\text { Atividade } \\
\text { silvicultural }\end{array}$ & $\begin{array}{c}\text { DAP médio } \\
\text { Altura total }\end{array}$ & $\begin{array}{c}\text { Altura comercial } \\
\text { média }\end{array}$ \\
\hline 3 & 2000 & 0 & Primeira poda & 10 & Não medida \\
6 & 2000 & 0 & Terceira poda & 16 & 8 \\
10 & 1600 & 0 & Terceira poda & 20 & 13 \\
12 & 1333 & 667 & Primeiro desbaste & 22 & 17 \\
14 & 1400 & 700 & Primeiro desbaste & 21 & 16 \\
16 & 800 & 400 & Segundo desbaste & 26 & 21 \\
24 & 550 & 550 & Corte raso & 33 & 11 \\
\hline
\end{tabular}

\footnotetext{
${ }^{6}$ Poder calorífico superior é a quantidade de calor total (energia térmica) que é liberado durante a combustão completa de uma unidade de massa ou de volume de combustível ( $\mathrm{kcal} / \mathrm{kg}$ ou $\mathrm{KJ} / \mathrm{Kg} ; \mathrm{kcal} / \mathrm{m}^{3}$ ou $\mathrm{KJ} / \mathrm{m}^{3}$ ). Para o cálculo do poder calorífico inferior é descontada a energia carga para a liberação do hidrogênio de constituição. No entanto, quando o combustível tiver umidade livre deve-se utilizar o poder calorífico inferior na base úmida ou poder calorífico líquido. Neste caso, além da energia perdida para a liberação do hidrogênio de constituição é descontada também a energia para evaporar a água livre do combustível (BRAND, 2010).
} 
Laboratório de Energia da Madeira da Universidade do Planalto Catarinense em 60 amostras mensais de biomassa florestal utilizadas na usina de cogeração.

- A produção de biomassa, por unidade de área, apresentada na Tabela 2 dos resultados.

- Um fator de conversão de 2,2 toneladas de biomassa para a geração de $1 \mathrm{MW} /$ hora de energia elétrica ${ }^{7}$.

- E no consumo médio de $200 \mathrm{KW} / \mathrm{hora} / \mathrm{mês}$ de energia elétrica de uma residência urbana.

Para análise estatística foi utilizado o software Statistica, em que foram aplicados o teste F e o teste de média de Tukey. Para a produção de biomassa, por árvore e por unidade de área, foram verificadas as variações ocorridas para cada componente (galhos, folhas e copa) entre as idades, para determinar qual a idade mais produtiva em cada tipo de biomassa produzida pela espécie. Para o teor de umidade e poder calorífico, foram avaliadas as variações em cada componente nas diferentes idades e também as variações entre os componentes na mesma idade, de forma a determinar o maior potencial de cada material e respectiva idade.

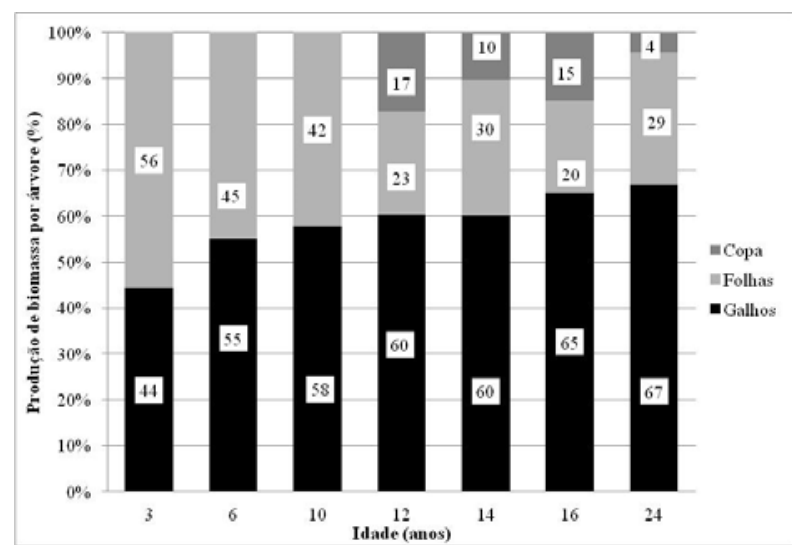

Figura 1 - Representação percentual de cada componente na biomassa florestal total por indivíduo, em cada idade.

Figure 1 - Percentage representation of each component in the total forest biomass per individual at each age.

Tabela 2 - Produção de biomassa dos componentes de Pinus taeda, nas diferentes idades.

Table 2 - Biomass production of components of Pinus taeda, at different ages.

\begin{tabular}{|c|c|c|c|c|c|}
\hline \multirow[t]{2}{*}{ Idade (anos) } & \multicolumn{5}{|c|}{ Peso dos componentes das árvores (kg/árvore) } \\
\hline & \multicolumn{2}{|l|}{ Galhos } & Folhas (acículas) & Сopa & Total \\
\hline 3 & \multicolumn{2}{|l|}{$6,73 \mathrm{~d}$} & $8,46 \mathrm{c}$ & 0,00 & 15 \\
\hline 6 & \multicolumn{2}{|l|}{$8,50 \mathrm{~cd}$} & $6,90 \mathrm{c}$ & 0,00 & 15 \\
\hline 10 & \multicolumn{2}{|l|}{20,55 bcd } & 15,05 bc & 0,00 & 36 \\
\hline 12 & \multicolumn{2}{|l|}{41,10 bcd } & 15,40 bc & 11,70 a c & 68 \\
\hline 14 & \multicolumn{2}{|l|}{54,90 bc } & $27,20 \mathrm{~b}$ & 9,30 bc & 91 \\
\hline 16 & \multicolumn{2}{|l|}{$57,00 \mathrm{ab}$} & 17,56 bc & 13,10 a & 88 \\
\hline 24 & 115,30 a & & 49,90 а & $7,40 \mathrm{~b}$ & 173 \\
\hline \multicolumn{6}{|c|}{ Produção de biomassa por unidade de área (toneladas/ha) } \\
\hline Idade(anos) & Galhos & Folhas & Copa & Total & Total sem folhas \\
\hline 3 & $13,46 \mathrm{~b}$ & $16,91 \mathrm{ab}$ & 0,00 & $30 \mathrm{~b}$ & $13 \mathrm{c}$ \\
\hline 6 & $17,00 \mathrm{~b}$ & $13,80 \mathrm{ab}$ & 0,00 & $31 \mathrm{~b}$ & $17 \mathrm{bc}$ \\
\hline 10 & $32,88 \mathrm{ab}$ & 24,08 a & 0,00 & $57 \mathrm{ab}$ & 33 bc \\
\hline 12 & $27,39 \mathrm{ab}$ & $10,26 \mathrm{~b}$ & 7,80 a & $45 \mathrm{~b}$ & 35 bc \\
\hline 14 & $38,43 \mathrm{ab}$ & $19,04 \mathrm{ab}$ & $6,51 \mathrm{ab}$ & $64 \mathrm{ab}$ & $45 \mathrm{ab}$ \\
\hline 16 & $22,80 \mathrm{~b}$ & 7,02 b & 5,24 bc & $35 \mathrm{~b}$ & 28 bc \\
\hline 24 & 63,42 a & 27,45 a & $4,07 \mathrm{c}$ & $95 \mathrm{a}$ & $67 \mathrm{a}$ \\
\hline
\end{tabular}

Nota: 1. Médias seguidas pela mesma letra dentro de cada componente (análise na coluna) não diferem significativamente pelo teste de Tukey; 2. Número de árvores por ha consideradas para o cálculo: 3 anos (2000 árvores); 6 anos (2000); 10 anos (1600); 12 anos (667); 14 anos (700); 16 anos (400); 24 anos (550).

Note: 1. Average followed by the same letter within each component (column analysis) did not differ significantly by Tukey test; 2. Number of trees per ha. used to calculate: 3 years (2000 trees); 6 years (2000); 10 years (1600); 12 years (667); 14 years (700); 16 (400); 24 years old (550).

${ }^{7}$ Este valor é baseado em valores de eficiência obtidos na co-geradora de energia UCLA - Tractebel Energia S.A.

Revista Árvore, Viçosa-MG, v.38, n.2, p.353-360, 2014 


\section{RESULTADOS}

\subsection{Quantidade de biomassa florestal para a geração de energia}

Na Tabela 2 e na Figura 1 são apresentados os resultados da determinação da produção de biomassa residual em cada idade, por árvore e por unidade de área. Na Figura 1 não aparece a quantidade de copa nas idades de 3, 6 e 10 anos, pois só foi retirada a massa das folhas e galhos das árvores no procedimento de poda.

\subsection{Qualidade da biomassa florestal para a geração de energia}

Na Tabela 3 são apresentados os valores médios individuais e totais do teor de umidade e poder calorífico de cada componente, em cada idade e nas diferentes etapas de manejo.

\subsection{Potencial de geração de energia elétrica a partir da biomassa florestal}

Na Tabela 4 são apresentados os resultados da capacidade de produção de energia elétrica a partir do uso da biomassa florestal obtida por unidade de área nas idades estudadas.

\section{DISCUSSÕES}

\subsection{Quantidade de biomassa florestal para a geração de energia}

A produção de biomassa por árvore variou de 15 kg/árvore (3 e 6 anos de idade, nas atividades de poda) até $173 \mathrm{~kg} /$ árvore (24 anos de idade, no corte raso). A quantidade de biomassa aumentou proporcionalmente com a idade, com a diminuição da proporção de folhas e aumento da proporção de galhos (Figura 1). Acima de 10 anos de idade, a quantidade

Tabela 3 - Propriedades energéticas dos componentes de Pinus taeda recém-colhido, em diferentes idades. Table 3 - Energetic properties of Pinus taeda componets recently harvested at different ages.

\begin{tabular}{|c|c|c|c|c|}
\hline Teor de umidade (\%) & $\mathrm{Copa}^{3}$ & Galho $^{3}$ & Folha $^{3}$ & Média $^{1}$ \\
\hline 3 anos & & $56 \mathrm{ab}$ & $52 \mathrm{a}$ & $54 \mathrm{~b}$ \\
\hline 10 anos & 62 a & 61 a & 63 a & 62 a \\
\hline 12 anos & 64 a & $50 \mathrm{ab}$ & $57 \mathrm{a}$ & $57 \mathrm{ab}$ \\
\hline 14 anos & 56 a & $59 \mathrm{ab}$ & 57 a & $57 \mathrm{ab}$ \\
\hline 16 anos & & $48 \mathrm{~b}$ & $61 \mathrm{a}$ & $54 \mathrm{~b}$ \\
\hline 24 anos & 62 a & 48 a & 56 a & $55 \mathrm{~b}$ \\
\hline Média $^{2}$ & $61 \mathrm{a}$ & $54 \mathrm{~b}$ & 58 a & \\
\hline Poder calorífico superior (kcal/kg) & $\mathrm{Copa}^{3}$ & Galho $^{3}$ & Folha $^{3}$ & Média $^{1}$ \\
\hline 3 anos & - & $4877 \mathrm{ab}$ & $5040 \mathrm{~b}$ & $4958 \mathrm{~b}$ \\
\hline 10 anos & $4898 \mathrm{ab}$ & $4812 \mathrm{~b}$ & $5096 \mathrm{~b}$ & $4935 \mathrm{~b}$ \\
\hline 12 anos & 4931 a & 4976 a & $5121 \mathrm{~b}$ & $5009 \mathrm{ab}$ \\
\hline 14 anos & $4820 \mathrm{~b}$ & $4844 \mathrm{~b}$ & $5113 \mathrm{~b}$ & $4923 \mathrm{~b}$ \\
\hline 16 anos & - & $4889 \mathrm{ab}$ & 5122 b & $5006 \mathrm{ab}$ \\
\hline 24 anos & $4933 \mathrm{ab}$ & 4977 a & 5258 a & 5059 a \\
\hline Média $^{2}$ & $4894 \mathrm{c}$ & 4896 c & $5125 \mathrm{~b}$ & \\
\hline Poder calorífico líquido (kcal/kg) & $\mathrm{Copa}^{3}$ & Galho $^{3}$ & Folha $^{3}$ & Média $^{1}$ \\
\hline 3 & - & 1654 abc & 1862 a & $1758 \mathrm{ab}$ \\
\hline 10 & 1338 a & 1389 с & 1340 a & $1356 \mathrm{~b}$ \\
\hline 12 & 1289 a & 1988 а с & 1641 a & $1639 \mathrm{ab}$ \\
\hline 14 & 1644 a & 1455 bc & 1633 a & $1579 \mathrm{ab}$ \\
\hline 16 & - & $2053 \mathrm{ab}$ & 1476 а & 1765 a \\
\hline 24 & 1393 а & 2113 a & 1807 a & $1780 \mathrm{a}$ \\
\hline Média² & $1420 \mathrm{C}$ & $1784 \mathrm{~b}$ & 1622 bc & \\
\hline
\end{tabular}

Nota: Médias seguidas pela mesma letra não diferem significativamente pelo teste de Tukey. 1 . Variação entre idades - análise na coluna; 2. Variação entre componentes (copa x galho x folha - análise na linha; e 3. Variação entre idades para cada componente separadamente - análise na coluna.

Note: Average followed by the same letter do not differ significantly by Tukey test. 1. Variation between ages - analysis column; 2. Variation between components (treetop x branch x leaf) - analysis in line; and 3 . Variation between ages for each component separately - analysis column. 
Tabela 4 - Potencial de produção de energia elétrica a partir do uso da biomassa florestal em sistemas de cogeração de energia. Table 4 - Potential production of electricity from the use of forest biomass in systems of cogeneration power.

\begin{tabular}{|c|c|c|c|c|c|}
\hline Idade & $\begin{array}{l}\text { Produção de } \\
\text { biomassa(t/ha) }\end{array}$ & $\begin{array}{l}\text { Produção energia } \\
\text { elétrica }(\mathrm{MW} / \mathrm{h})\end{array}$ & $\begin{array}{l}\text { Número de casas } \\
\text { atendidas(Mês) }\end{array}$ & $\begin{array}{l}\text { Produção de energia } \\
\text { elétrica }(\mathrm{KW} / \mathrm{h})\end{array}$ & $\begin{array}{c}\text { Número de casas } \\
\text { atendidas(hora) }\end{array}$ \\
\hline 3 & 30 & 14 & 68 & 13636 & 49.091 \\
\hline 6 & 31 & 14 & 70 & 14091 & 50.727 \\
\hline 10 & 57 & 26 & 130 & 25909 & 93.273 \\
\hline 12 & 45 & 20 & 102 & 20455 & 73.636 \\
\hline 14 & 64 & 29 & 145 & 29091 & 104.727 \\
\hline 16 & 35 & 16 & 80 & 15909 & 57.273 \\
\hline 24 & 95 & 43 & 216 & 43182 & 155.455 \\
\hline
\end{tabular}

de galhos e copa excede $70 \%$ do total de biomassa residual produzido por indivíduo, o que é interessante principalmente nos casos em que se recomenda a manutenção das folhas no campo, para minimizar a exportação de nutrientes.

A quantidade de biomassa da copa diminui nas árvores mais velhas, concordando com Santana (2008), que observou o mesmo fenômeno na quantificação de biomassa em Eucalyptus. Isso porque o crescimento em altura tende a diminuir e ocorrer a maior formação de galhos, como pode ser observado na Figura 1. Povoamentos mais velhos e com maior espaçamento entre indivíduos tendem a tomar forma mais cônica.

A comparação entre médias da quantidade de biomassa por árvore, pelo teste de Tukey, demonstrou que a produção de galhos e folhas teve a tendência de formar grupos similares, agregando diferentes idades a esses grupos. Tanto para folhas quanto para os galhos, a produção foi similar entre 3 e 12 anos (Tabela 2), formando grupos estatisticamente iguais. Um segundo grupo foi formado pelas idades de 10 a 16 anos (Tabela 2). Já a idade de 24 anos se comportou de forma diferente, tendo maior produção, tanto de galhos quanto de folhas. No entanto, mesmo que a análise estatística tenha agrupado idades, pode-se perceber que a produção teve grande variação mesmo dentro dos grupos de idades. Considerando a idade, os indivíduos com maior produção de biomassa foram os com 24, 14 e 16 anos, respectivamente.

Nas diferentes idades, o sistema de manejo e as práticas silviculturais têm influência sobre o número de indivíduos remanescentes por unidade de área e a quantidade de biomassa extraída da floresta.

A produção de biomassa por unidade de área variou de 30 (3 e 6 anos) a 95 t/ha (24 anos). Se não forem incluídas na soma da quantificação da biomassa das folhas, o potencial varia de 13 a $67 \mathrm{t} / \mathrm{ha}$, nas idades de 3 e 24 anos, respectivamente. Assim, o maior potencial produtivo de biomassa está no corte raso (24 anos), mesmo tendo número menor de indivíduos por unidade de área (550). Árvores com maior idade produziram maior quantidade individual de biomassa. Assim, mesmo com a redução no número de indivíduos por unidade de área, promovida pelos desbastes, o maior potencial produtivo de biomassa está nas maiores idades.

Tanto para os galhos quanto para as folhas, a maior produção foi no corte raso. Para os galhos, o primeiro desbaste (14 anos) se destacou como a segunda maior produção, enquanto a idade de 10 anos teve a segunda maior produção de biomassa na forma de folhas. Portanto, as situações com maior potencial de biomassa para a geração de energia são o corte raso (24 anos), primeiro desbaste (14 anos) e terceira poda (10 anos). Em contrapartida, as situações de menor potencial são a primeira e a terceira poda (3 e 6 anos). Além disso, deve-se considerar que o custo operacional e as dificuldades de locomoção dentro do povoamento, coleta, retirada da biomassa e transporte na poda são maiores que nas demais operações silviculturais.

O preço médio pago na região de Lages, SC, em 2012, pela biomassa florestal para a geração de energia é de R\$ 52,00/tonelada, a renda nas operações silviculturais com o uso da biomassa para geração de energia pode variar de $\mathrm{R} \$ 676,00 /$ ha na condição de permanência das folhas na floresta até $\mathrm{R} \$ 4.940,00 /$ ha na condição de extração da biomassa em corte raso.

\subsection{Qualidade da biomassa florestal para a geração de energia}

Todos os componentes (galhos, folhas, copa) apresentam alto teor de umidade. Segundo Garstang et al. (2002), a biomassa para a geração de energia deve apresentar teores de umidade iguais ou inferiores a 30\%. 
Verificou- que a copa e as folhas tiveram maior teor de umidade, enquanto os galhos apresentaram menor valor. O aumento da idade promoveu redução do teor de umidade, porém não de maneira a melhorar a eficiência de conversão da biomassa em energia. Dessa forma, o tipo de componente (galhos, folhas ou copa) demonstrou ter maior influência sobre a variação no teor de umidade que a idade das árvores.

O poder calorífico superior é influenciado pela composição química da biomassa (THÖRNQVIST, 1986; SJÖSTRÖM, 1993; JIRJIS, 1995; GARSTANG et al., 2002), havendo variação entre os componentes avaliados. Os valores foram de 4.800 a $5.200 \mathrm{kcal} / \mathrm{kg}$, com maiores valores de folhas e menores de copa e galhos. As folhas possuem maior conteúdo de extrativos, que aumentam o poder calorífico da biomassa.

O poder calorífico superior variou proporcionalmente em relação à idade, com maiores valores nas idades de 24, 12 e 16 anos e ligeiramente inferiores nas demais idades. Em termos práticos, para uso da biomassa para a geração de energia são consideradas importantes variações superiores a $300 \mathrm{kcal} / \mathrm{kg}$ (BRAND, 2010), o que não foi observado entre os materiais e entre as idades. Assim, pode-se considerar que a eficiência de conversão energética tanto dos materiais quanto das idades será similar para um mesmo teor de umidade.

O poder calorífico líquido variou de 1.300 a $2.100 \mathrm{kcal} / \mathrm{kg}$, com maiores valores nas maiores idades (24 e 16 anos) e no componente galho.

O poder calorífico líquido está estreitamente relacionado ao teor de umidade, e quanto maior o teor de umidade, menor o poder calorífico. Assim, os galhos que apresentaram menor teor de umidade tiveram os mais altos valores de poder calorífico líquido, constituindo-se no melhor material para a geração de energia.

No entanto, considerando que o teor de umidade é alto e que o poder calorífico líquido mínimo desejado para biomassa usada em plantas de cogeração de energia é de $1.900 \mathrm{kcal} / \mathrm{kg}$, nenhum dos materiais avaliados terá bom desempenho energético sem um tratamento prévio para a redução do teor de umidade.

\subsection{Potencial de geração de energia elétrica a partir da biomassa florestal}

Considerando o potencial de produção de biomassa nas diferentes idades e sistemas de manejo, a menor capacidade produtiva, 30 t/ha (3 anos), o potencial de produção de energia elétrica seria suficiente para abastecer 68 residências/mês com consumo médio de 200 kW/hora/mês ou, então, 49.000 residências durante $1 \mathrm{~h}$.

Na maior capacidade produtiva de biomassa, 95 t/ha (24 anos), poder-se-ia fornecer energia elétrica para 216 casas/mês ou abastecer 155.455 casas durante 1 h, através da combustão da biomassa para geração de energia elétrica em um sistema de cogeração.

Esses números demonstram o grande potencial de geração de energia elétrica a partir do uso de biomassa florestal oriunda de atividades silviculturais e que, atualmente, é deixada na floresta sem uso. Esses resultados apoiam as conclusões obtidas por Soares et al. (2003), que defendem o uso da biomassa florestal para uso múltiplo.

\section{CONCLUSÕES}

\subsection{Quantidade de biomassa}

- A produção de biomassa florestal por árvore é diretamente proporcional à idade.

- O aumento da idade proporciona maior produção e galhos e redução da produção de folhas e copa.

- O sistema de manejo e as práticas silviculturais têm influência, juntamente com a idade, na produção de biomassa por unidade de área.

- O maior potencial produtivo de biomassa para a geração de energia são o corte raso (24 anos), o primeiro desbaste (14 anos) e a terceira poda (10 anos), respectivamente.

\subsection{Qualidade da biomassa}

- O material com melhor qualidade para geração de energia é o galho, pois possui o menor teor de umidade e o maior poder calorífico líquido.

- O tipo de componente teve maior influência na qualidade energética da biomassa do que a idade.

- A qualidade da biomassa recém-colhida é baixa para geração de energia, necessitando de tratamento prévio para redução do teor de umidade e aumento do poder calorífico líquido.

Revista Árvore, Viçosa-MG, v.38, n.2, p.353-360, 2014 


\subsection{Potencial de geração de energia elétrica a partir da biomassa florestal}

- O potencial de geração de energia elétrica a partir da biomassa florestal residual é alto por unidade de área e justifica o incentivo dessa fonte como alternativa para a produção de energia limpa.

\section{AGRADECIMENTOS}

À Tractebel S.A., pelo apoio financeiro para a realização das atividades do projeto.

À Flobasa, por permitir o acesso aos seus povoamentos e o uso de seus materiais.

À EMBRAPA Florestas, pela concessão de bolsas a dois dos autores.

À Universidade do Planalto Catarinense (UNIPLAC), pela utilização de suas dependências e concessão de bolsas a integrantes do grupo de pesquisa.

\section{REFERÊNCIAS}

ABRAF. Anuário Estatístico da Associação Brasileira de Produtores de Florestas Plantadas. ABRAF 2012: ano base 2011/ABRAF Brasilia: 2012. 150p.

\section{ASSOCIAÇÃO BRASILEIRA DE NORMAS} TÉCNICAS. NBR 14929. Madeira - Determinação do teor de umidade de cavacos - Método por secagem em estufa. Rio de Janeiro: 2003.

\section{BRAND, M. A. Energia de biomassa} florestal. Rio de Janeiro: Interciência, 2010. 131p.

BRAND, M. A.; NEVES, M. D. Levantamento da disponibilidade dos resíduos florestais de madeira e avaliação da variação de sua qualidade energética em função da condições climáticas anuais na região de Lages-Santa Catarina. Lages: Universidade do Planalto Catarinense, 2005. (Relatório Técnico)

BRAND, M. A. et al. Caracterização da produção e uso dos resíduos madeiráveis gerados na indústria de base florestal da região serrana catarinense. Lages: Universidade do Planalto Catarinense, 2001. (Relatório Técnico)
BRAND, M. A. et al. Parâmetros de controle da qualidade e preço da biomassa florestal para a geração de energia. Revista ANEEL, n.3, p.36-38, 2009.

\section{DEUTSCHES INSTITUT FÜR NORMUNG e. V.} DIN 51900. Determining the gross calorific value of solid and liquid fuels using the bomb calorimeter, and calculation of net calorific value. Berlim: 2000.

GARSTANG, J. et al. Identification and characterisation of factors affecting losses in the large-scale, nonventilated bulkstorage of wood chips and development of best storage practices. Report. FES B/W2/00716/RESP.DTI/ Pub urn 02/1535: 2002. 116p.

HOFF, D. N. et al. O setor de base florestal da Serra Catarinense e a emergência de um ecossistema industrial. Revista de Gestão Social e Ambiental - RGSA, v.2, p.54-72, 2008.

JIRJIS, R. Storage and drying of wood fuel. Biomass and Bioenergy, v.9, n.1-5, p.181190, 1995.

BRASIL. Ministério de Minas e Energia.

Balanço Energético Nacional: Ano Base 2010. Rio de Janeiro: EPE, 2011. 266p.

SANTANA, R. C. et al. Estimativa de biomassa de plantios de eucalipto no Brasil. Revista Árvore, v.32, n.4, p.697-706, 2008.

SJÖSTRÖM, E. Wood chemistry.

Fundamentals and applications. 2.ed. New York: Academic Press, 1993. 293p.

SOARES, T. S. et al. Otimização de multiprodutos em povoamentos florestais. Revista Árvore, v.27, n.6, p.811-820, 2003.

THÖRNQVIST, T. Projekt storskalig säsongslagring av trädbraänsle - en sammanfattning av etapp 1. Largescale seasonal storage of tree fuel project summary of phase 1 . Sweden: The Swedish University of Agricultural Sciences.

Department of Forest Products, 1986. 50p. (Report $n^{\circ} 188$ ) 